\title{
Mechanisms by Which SARS-CoV-2 May Impact Male Fertility
}

\author{
Albert L. Hsu ${ }^{1,2}$ (D) Alex Finlinson ${ }^{1,2} \cdot$ Kristen Warncke ${ }^{3}$ \\ Received: 15 August 2020 / Accepted: 24 August 2020 / Published online: 6 October 2020 \\ (C) Society for Reproductive Investigation 2020
}

\begin{abstract}
The COVID-19 pandemic is unlike anything we have experienced in over a century. In the USA, waves of COVID-19 have migrated from the Northeast to the Sun Belt to the Midwest over the past year. Compared with females, males are more susceptible to SARS-CoV-2 infection, have more severe COVID-19 disease, and have higher death rates. In many countries, men are consistently more likely to die by a factor of almost 2 . This article describes some of the mechanisms by which COVID19 may be associated with male infertility, as discussed by Dutta and Sengupta.
\end{abstract}

Keywords COVID-19 $\cdot$ SARS-CoV-2 $\cdot$ Male fertility

\section{Dear Editor:}

The global number of COVID-19 cases is inexorably rising, with over 33 million worldwide cases reported by the Johns Hopkins Coronavirus Resource Center (as of 9/30/20). There are also marked sex differences in the incidence and severity of COVID-19 cases; in humans, males are more susceptible to SARS-CoV-2 infection compared with agematched females. Men are also more likely to be managed in intensive care or even die from COVID-19. Dutta and Sengupta have detailed the potential impact of COVID-19 on male reproductive function as well as some mechanisms by which COVID-19 may potentially be associated with male infertility [1].

Angiotensin-converting enzyme 2 (ACE2) is the receptor for SARS-CoV-2 and is differentially regulated in males and females. Cells with high levels of ACE2 expression have the potential to be targeted and damaged by SARS-CoV-2 . Single-cell transcriptome studies have revealed abundant

\section{Albert L. Hsu}

hsual@alum.mit.edu

University of Missouri Health Care, Columbia, MO, USA

2 Department of Obstetrics, Gynecology and Women's Health, MU Institute for Women's Health Research, University of Missouri School of Medicine, 500 North Keene Street, Columbia, MO 65201, USA

3 University of Missouri School of Medicine, Columbia, MO, USA
ACE2 expression in Sertoli cells, Leydig cells, and spermatogonia, rendering all three categories of testicular cells potentially vulnerable to cellular damage by SARS-CoV-2 [2].

Cellular entry of SARS-CoV-2 is mediated by its spike glycoproteins (S proteins), which need priming by cellular proteases to facilitate viral fusion to cellular membranes. TMPRSS2 (transmembrane protease serine 2) is utilized for $\mathrm{S}$ protein priming and is found in prostate epithelial cells [3, 4]; androgen receptor activation is needed to trigger TMPRSS2 expression [1]. In addition, brain cells (neurons and glial cells) also express ACE2 receptors, raising the question of whether viral damage by SARS-CoV-2 may also disrupt the hypothalamic-pituitary-testicular axis and thereby disrupt normal male pubertal development and/or contribute to male infertility [2].

There is some evidence correlating high ACE2 expression with infertility, suggesting that "an overactivation of ACE2 might affect spermatogenesis." [2] Of note, the highest number of ACE2-positive cells was found in a 30-year-old man (compared with a 20-year-old and 60-year-old man) [1]. As the COVID-19 pandemic evolves to strike younger populations of reproductive age globally, it remains an outstanding question whether there will be a rise in male factor infertility (or overall infertility) in general, as a result of this pandemic.

Dutta and Sengupta discuss oxidative stress, inflammation, and the immunologic response to a high testicular viral load in the testes, as parts of a cascade that could lead to COVID-19-related male factor infertility [1]. Evidence of localized testicular damage also suggests the potential for adverse reproductive consequences at 
the anatomical, cellular, and molecular levels. With evidence that worldwide sperm counts have already declined 50-60\% among men in North America, Europe, Australia, and New Zealand between 1973 and 2011 [5], the potential impact of COVID-19 on sperm and sperm function is an area that requires urgent further study.

\section{Compliance with Ethical Standards}

Conflict of Interest The authors declare that they have no conflict of interest.

\section{References}

1. Dutta S, Sengupta P. SARS-CoV-2 and male infertility: possible multifaceted pathology. Reprod Sci. 2020:1-4. https://doi.org/10. 1007/s43032-020-00261-z.
2. Vishvkarma R, Rajender S. Could SARS-CoV-2 affect male fertility? Andrologia. 2020:e13712. https://doi.org/10.1111/and.13712.

3. Paoli D, Pallotti F, Turriziani O, et al. SARS-CoV-2 presence in seminal fluid: myth or reality. Andrology. 2020. https://doi.org/10. 1111/andr.12825.

4. Corona G, Baldi E, Isidori AM, Paoli D, Pallotti F, de Santis L, et al. SARS-CoV-2 infection, male fertility and sperm cryopreservation: a position statement of the Italian Society of Andrology and Sexual Medicine (SIAMS) (Società Italiana di Andrologia e Medicina della Sessualità). J Endocrinol Investig. 2020;43(8):1153-7. https://doi. org/10.1007/s40618-020-01290-w.

5. Levine H, Jørgensen N, Martino-Andrade A, Mendiola J, WekslerDerri D, Mindlis I, et al. Temporal trends in sperm count: a systematic review and meta-regression analysis. Hum Reprod Update. 2017;23(6):646-59. https://doi.org/10.1093/humupd/dmx022.

Publisher's Note Springer Nature remains neutral with regard to jurisdictional claims in published maps and institutional affiliations. 